\title{
CORRESPONDENCE
}

\section{Educating Chemists}

SIR,-Y Your recent notes ${ }^{1}$ about education in chemistry seem to me to present an argument in a circle, or rather a descending helix.

There is no doubt that there is a demand for chemists trained in the classical manner. In the opinion of the majority of teachers this training requires a course which involves much work that may be unacceptable to many students. There is no certainty exactly what the size of the demand is. I have maintained for years that it was much less than it is generally said to be and that chemistry departments were being expanded far too much. The reasons for this may be many, but certainly include empire building.

Now we are reaching a situation in the UK where chemists find it difficult to obtain jobs and chemistry departments find it difficult to obtain students. One answer that is given is that chemists should be employed in other jobs than chemistry. You are rightly scornful of this, and say instead that chemists should be trained in all sorts of things other than chemistry. I think this is also evading the issue, which is simply that UK chemistry departments are trying to take too many students and should contract. I can see how popular this answer would be, but the fault lies squarely with the expansionists.

I agree there may be a demand for people trained as you suggest, and I am all in favour of this being done, but please do not let us confuse them with chemists, otherwise the next stage will be a shortage of properly trained chemists.

In passing, I think that organic chemistry at least is pedagogically an intrinsically unsatisfactory subject. Although it has a very beautiful theoretical structure it is impossible to appreciate this without knowing many facts, which themselves appear unrelated until one understands the theory.

Yours faithfully,

$$
\text { D. A. H. TAYLOR }
$$

Department of Chemistry, University of Ibadan, Nigeria

${ }^{1}$ Nature, 228, 1242 (1970).

\section{Wordsworth and Science}

SrR,-Readers of the recent article on Wordsworth and Hamilton ${ }^{1}$ may be interested in knowing that Wordsworth's interest in natural science, or, at least, ratural phenomena, can be traced back to his early years. He numbered among his friends the blind botanist John Gough $^{2}$, whom he described in one of his poems:

Methinks I see him-how his eyeballs

Beneath his ample brow, in darkness rolled

But each instinct with spirit, and the paired;

Of the whole countenance alive with frame

Fancy, and understanding; while the hought.

Discoursed of natural and moral truth With eloquence, and such authentic

power,

That in his presence humbler knowledge stood

Abashed, and tender pity overawed.

The Wordsworths' admiration for Gough is evidenced in Dorothy's recommendation of him as a tutor ${ }^{3}$. The lines reflect Wordsworth's attitude toward scientists: he admired those with the perspective to see their work as a part of the unity of nature and man in all their aspects, and scorned those who were completely wrapped up in details and who could never see the general view ${ }^{4}$.

Wordsworth was a keen observer of nature, and had, in particular, a very sensitive ear which resulted in many aural references in his poetry ${ }^{5}$. An interesting aspect of this sensitivity is his reference to the sound of the aurora in a poem of 1798 , for which he used Hearne's description as a basis. He does not state that he has himself heard these sounds. The Wordsworths were, however, from the north of England, and auroral sounds have been reported from there. John Dalton kept a record of auroral observations at Kendal from 1786-1793, and reports for the intense aurora of May 24, 1788 , that sounds were reported. He also later notes the prevailing opinion that auroral sounds occurred. Wordsworth was, of course, quite familiar with Kendal and its vicinity from at least 1794 (ref. 6), and it is likely that he was familiar with local reports of auroral sounds. Dalton was a pupil of John Gough, the friend of Wordsworth, and it would be interesting to know if there is any evidence to indicate that Wordsworth and Dalton also knew each other. If this could be shown to be the case, then Wordsworth's connexion with another of the great men of nineteenth century science would be more firmly established.

Yours faithfully, SAM Silverman

Polar Atmospheric Processes Branch, Aeronomy Laboratory,

Bedford, Massachusetts 01730

1 Dodd, G., Nature, 228, 1261 (1970).

2 Watson, J., Annals of a Quiet Valley in the Wordsworth Country (Dent, London, 1894).

3 Wordsworth, Dorothy, in The Letters of William and Dorothy Wordsworth: The Middle Years (edit. by de Selincourt, E.), 2, 565, 571, and 581 (Clarendon Press, Oxford, 1937).

${ }^{4}$ Watson, R. S., in Wordsworthiana (edit. by Knight, W.), 199 (Macmillan, London, 1889).

5 Heard, W. A., in Wordsworthiana (edit. by Knight, W.), 219 (Macmillan, London, 1889).

${ }^{6}$ de Selincourt, E., The Early Letters of William and Dorothy Wordsworth, 110, 242 (Clarendon Press, Oxford, 1935).

\section{Junctions between Muscle Fibres}

Sir,-In a recent letter to Nature ${ }^{1}$, I described junctions between muscle fibres in cat extraocular muscles, and stated that these had not previously been reported. It has been brought to my notice that such junctions had already been described by Mayr, Zenker and Gruber ${ }^{2}$ in extraocular muscles of birds, and by Teräväinen $^{3}$ in extraocular and diaphragm muscles of rats. I wish to apologize to the authors concerned for my oversight.

Yours faithfully,

$$
\text { K. FLOYD }
$$

Department of Physiology,

University College London,

Gower Street,

London WC1

1 Floyd, K., Nature, 227, 185 (1970).

2 Mayr, R., Zenker, W., and Gruber, H., $Z$. Zellforsch., 79, 319 (1967).

3 Teräväinen, H., Experientia, 25, 524 (1969). 